Document downloaded from:

http://hdl.handle.net/10251/51590

This paper must be cited as:

González Espín, FJ.; Gabriel Garcerá; Patrao Herrero, I.; Figueres Amorós, E. (2012). An Adaptive Control System for Three-Phase Photovoltaic Inverters Working in a Polluted andVariable Frequency Electric Grid. IEEE Transactions on Power Electronics. 27(10):4248-4261. doi:10.1109/TPEL.2012.2191623.

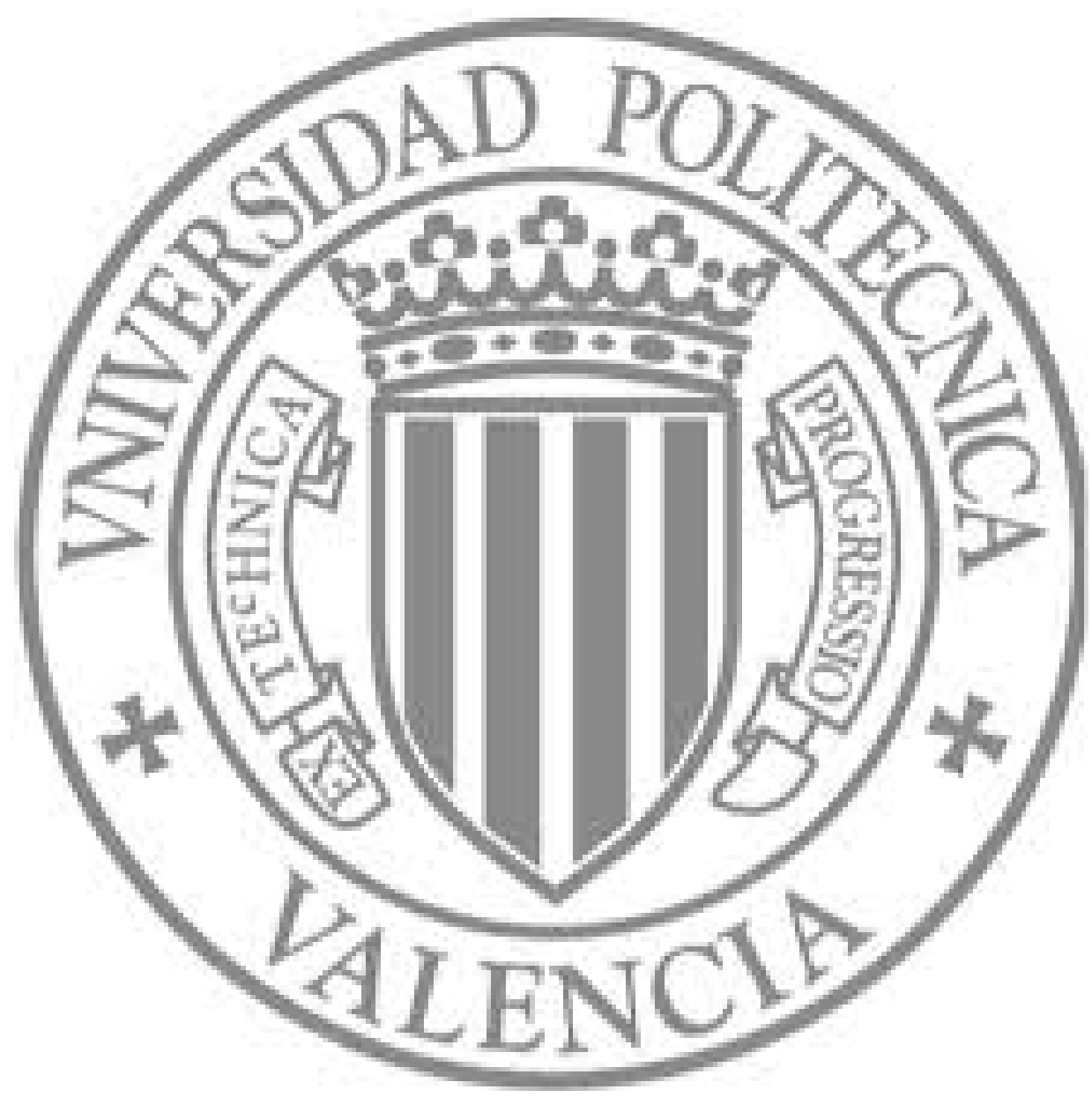

The final publication is available at

http://ieeexplore.ieee.org/xpl/articleDetails.jsp?arnumber=6172589

Copyright Institute of Electrical and Electronics Engineers (IEEE) 


\title{
An Adaptive Control System for Three-Phase Photovoltaic Inverters Working in a Polluted and Variable Frequency Electric Grid
}

\author{
Fran González-Espín, Member, IEEE, Gabriel Garcerá, Member, IEEE, \\ Iván Patrao, Emilio Figueres, Senior Member, IEEE
}

\begin{abstract}
The control of grid connected photovoltaic Voltage Source Inverters (VSI) in the Stationary Reference Frame (StRF) by means of the Proportional+Resonant (PR) controller, has been proposed in the past as a convenient method to control the injected current. As this control technique needs the estimation of the grid voltage frequency, the Synchronous Reference Frame Phase-Locked Loop (SRF-PLL) is commonly added to the control scheme. However, this control strategy cannot cope with the variation of the grid frequency. Furthermore, the conventional SRF-PLL cannot properly reject the disturbances of the grid voltage, mainly if its frequency varies. To assure a low Total Harmonic Distortion of the injected current (THDi), even if the grid voltage is polluted and its frequency varies, an adaptive control system is presented in this paper, which can improve the behavior of both, the conventional SRF-PLL and the conventional PR controller. The proposed adaptive control system has been tested by means of a digitally controlled $10 \mathrm{KVA}$ inverter, plugged into a polluted grid with a time varying frequency. The experimental results show up that the THDi of the injected current is improved when using the proposed adaptive control method instead of the conventional one.
\end{abstract}

Index Terms - Digital control, linear feedback control systems, power system harmonics, power quality, three-phase electric power, adaptive signal processing, adaptive filters, lattice filters.

\section{INTRODUCTION}

$\mathrm{T}$ he use of distributed energy resources is changing the electric generation paradigm [1]. Basically, the electric grid is expected to turn into a more flexible system, where some real-time varying parameters will have to be considered. Thus, it is important to develop control algorithms which are able to real-time adapt their behavior in order to fulfill these new challenges. One of the most studied topics about the

This work was supported by the Spanish Ministry of Science and Innovation under Grants ENE2009-13998-C02-02.

F. Gonzalez-Espin (e-mail: fgonzalezespin@gmail.com), G. Garcera, I. Patrao and E. Figueres are with the Grupo de Sistemas Electrónicos Industriales del Departamento de Ingeniería Electrónica de la Universitat Politècnica de València, Camino de Vera S/N (Edificio 7F), 46022 Valencia, Spain. upcoming microgrids is its feasibility to work in the islanded mode [2], [4]. In this mode of operation, the state-of-the-art suggests using the droop control method to operate the static converters in the microgrid, so that the delivered reactive and active power can be controlled by means of the generated voltage amplitude and voltage frequency, respectively. In this regard, the controllers implemented in the power converters connected to the microgrid must take into account the variable frequency feature, as well as the possible pollution in the voltage of the microgrid (i.e. voltage unbalance, voltage harmonic distortion, or voltage dips) [5], [6].

Although several control methods can be found that cope with a polluted electric grid, most of them perform well just in case the voltage frequency is fixed. That is the case of the Proportional+Resonant (PR) based control strategy [8], which is able to follow a sinusoidal reference while rejecting its undesired harmonics. Furthermore, only a PR controller is needed to control both the positive and the negative sequence of a given harmonic [7]. However, the ideally infinite gain of the control action can be only assured for a given frequency, so that for the PR controller to work properly, the frequency of the reference to be tracked must be fixed.

To avoid this problem, the Multiple Synchronous Reference Frame (MSRF) control strategy can be used [8], [9]. This control strategy uses a reference frame synchronized with the positive sequence of the fundamental harmonic and as many reference frames as harmonics have to be rejected. As long as each reference frame is synchronized with the corresponding harmonic, this control strategy is able to cope with the frequency variations. However, this control method requires a high computational effort. Additionally, the uncertainty about the amplitude of the grid voltage harmonics negatively affects the performance of the MSRF [10].

Another important issue that has to be solved in a grid connected inverter is the synchronization with the electric grid. The Synchronous Reference Frame Phase Locked Loop (SRF PLL) is a well-known method to carry out this task, because of its simplicity and robustness [11]. Nevertheless, if the Point of Common Coupling (PCC) of the inverter is polluted, the estimation of the phase will not be as accurate as required [12], [13].

Although several techniques have been proposed to avoid for the voltage harmonics in the electric grid to appear in the 
estimated phase, those techniques do not usually take into account the variation of the grid voltage frequency [14], [15]. To cope with this problem, some authors have proposed a simple adaptive resonant filter structure [16], [17] or a lead compensator [18]. Nevertheless, the stability of the adaptive filter is not studied in those methods, so that the stability of the whole SRF-PLL cannot be assured under all circumstances.

Other approaches to obtain an accurate estimation of the voltage phase can be found in the literature [10], [19], [20], [30], which cope with frequency variations. In [30], an adaptive filtering method is proposed which is based on varying the sampling frequency. However, for the sampling frequency to be varied, the switching frequency is also required to do so, which might not be a good solution. The method in [19] uses a multiple synchronous reference frame to detect the positive and the negative sequence grid voltage components, so that the voltage unbalance effect in the estimated phase is avoided, whereas the method in [20] is insensitive to the variation of the voltage frequency. In [10] the MSRF concept is used to accurately estimate the voltage frequency. However, the complexity of the estimation process increases notably respect to the conventional SRF-PLL algorithm.

This paper proposes an integrated adaptive control system composed of a synchronization algorithm and a control method. This control system is intended to be used in three phase grid connected photovoltaic inverters. The proposed control system is able to provide a low THDi and a high PF even if the voltage frequency of a polluted electric grid varies. The synchronization method is based on the conventional SRF-PLL, whereas the controller is based on the conventional PR controller. The adaptive feature has been added by means of the inherently stable Schur-lattice IIR filter [21], and is able to cope with the frequency voltage varieations.

The paper is organized as follows. In Section II, a model of the three-phase photovoltaic inverter in the Stationary Reference Frame (StRF) is presented, along with the conventional PR control scheme. In Section III, the behavior of the PR and of the SRF-PLL is studied when the voltage grid is polluted and its frequency varies. Section IV presents the adaptive Schur-lattice IIR structure, including the numeric and the stability properties which make it a suitable choice to implement filters in the digital domain. In Section V, the adaptive control system is presented and in Section VI experimental results are shown, whereas in Section VII a set of conclusions are presented.

\section{Modeling And CONTROL OF THE GRID-CONNECTED Three-Phase Photovoltaic InVERTER IN THE STRF}

In Fig. 1 it is shown the commonly used StRF control strategy of the grid connected three phase photovoltaic inverter. The control stage mainly comprises the synchronization algorithm, the inverter output current control stage and the PV array voltage control stage, along with the maximum power point tracking (MPPT) algorithm.

On the one hand, the synchronization algorithm is based on the well-known SRF-PLL technique. On the other hand, the control of the PV output voltage is accomplished by means of a conventional Proportional+Integral (PI) controller, whereas the control of the inverter output current is carried out in the StRF by using the PR controller. As previously stated, this controller offers a good tracking of the sinusoidal reference signal, and a good rejection of the positive and negative undesired harmonics.

To properly design the controllers, a linear model of the grid-connected PV inverter is needed. This model has been obtained by using the schematic depicted in Fig. 2. This schematic includes the $\mathrm{PV}$ array (modeled by its $i_{P V^{-}} v_{P V}$ curve), the DC-link capacitance, $C_{P V}$, the output filter composed of the filter inductance, $L_{i}$, the filter capacitance, $C_{f}$, and the damping resistor, $R_{d}$, along with the transformer leakage inductance, $L_{g}$. The parasitic resistors of the inductors have been also considered (i.e. $R_{i}$ and $R_{g}$ ), and that the

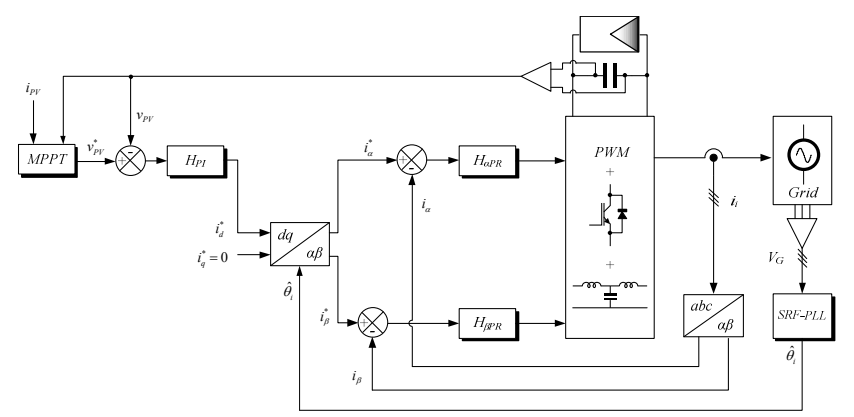

Fig. 1. Simplified schematic of the conventional control strategy in the StRF.

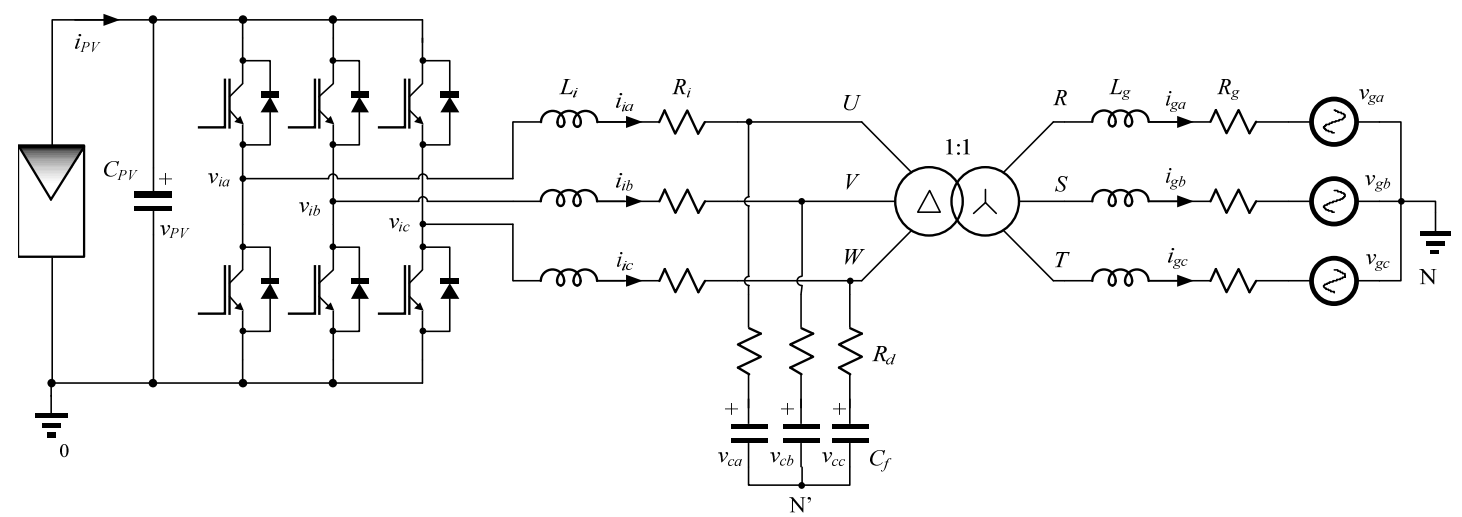

Fig. 2. Grid connected photovoltaic inverter. 
parasitic grid inductance has been included into $L_{g}$ [22] .

By operating in Fig. 2, the space-state average model of the three-phase inverter defined by (1), (2), (3), (4), (5) and (6) has been obtained. In this small-signal average model, $D_{\alpha}, D_{\beta}$, $I_{\alpha}, I_{\beta}$ are the operating point values of the duty cycle, $d$, and of the inverter current, $i_{i}$, in the $\alpha$ and $\beta$ channels, respectively. The constant $k_{P V}=-I_{P V} / V_{P V}$ is the transconductance of the $\mathrm{PV}$ array around the chosen operating point.

$$
\begin{aligned}
& \overrightarrow{\dot{x}}=A \cdot \vec{x}+B \cdot \vec{u} \\
& \vec{y}=C \cdot \vec{x}+D \cdot \vec{u} \\
& A=\left[\begin{array}{ccccccc}
-\left(\frac{R_{i}+R_{d}}{L_{i}}\right) & 0 & \frac{R_{d}}{L_{i}} & 0 & -\frac{1}{L_{i}} & 0 & \frac{D_{\alpha}}{L_{i}} \\
0 & -\left(\frac{R_{i}+R_{d}}{L_{i}}\right) & 0 & \frac{R_{d}}{L_{i}} & 0 & -\frac{1}{L_{i}} \frac{D_{\beta}}{L_{i}} \\
\frac{R_{d}}{L_{g}} & 0 & -\left(\frac{R_{g}+R_{d}}{L_{g}}\right) & 0 & \frac{1}{L_{g}} & 0 & 0 \\
0 & \frac{R_{d}}{L_{g}} & 0 & -\left(\frac{R_{g}+R_{d}}{L_{g}}\right) & 0 & \frac{1}{L_{g}} & 0 \\
\frac{1}{C_{f}} & 0 & -\frac{1}{C_{f}} & 0 & 0 & 0 & 0 \\
0 & \frac{1}{C_{f}} & 0 & -\frac{1}{C_{f}} & 0 & 0 & 0 \\
-\frac{D_{\alpha}}{C_{P V}} & -\frac{D_{\beta}}{C_{P V}} & 0 & 0 & 0 & 0 & \frac{k_{P V}}{C_{P V}}
\end{array}\right] \\
& B=\left[\begin{array}{cccc}
V_{P V} / L_{i} & 0 & 0 & 0 \\
0 & V_{P V} / L_{i} & 0 & 0 \\
0 & 0 & -1 / L_{g} & 0 \\
0 & 0 & 0 & -1 / L_{g} \\
0 & 0 & 0 & 0 \\
0 & 0 & 0 & 0 \\
-I_{\alpha} / C_{P V} & -I_{\beta} / C_{P V} & 0 & 0
\end{array}\right] \\
& \vec{x}=\vec{y}=\left[\begin{array}{lllllll}
\tilde{i}_{i \alpha} & \tilde{i}_{i \beta} & \tilde{i}_{g \alpha} & \tilde{i}_{g \beta} & \tilde{v}_{c \alpha} & \tilde{v}_{c \beta} & \tilde{v}_{P V}
\end{array}\right]^{T} \\
& \vec{u}=\left[\begin{array}{llll}
\tilde{d}_{\alpha} & \tilde{d}_{\beta} & \tilde{v}_{g \alpha} & \tilde{v}_{g \beta}
\end{array}\right] \\
& C=I, \quad D=0
\end{aligned}
$$

Each of the parameters can be analytically obtained by means of the expressions shown in Table I, where the $V_{P V}$ and $I_{P V}$ values are usually chosen to be the voltage and the current of the PV array at the maximum power point (MPP); however, other operating points can be considered. It is worth pointing out that the operating point of the inverter in the StRF, depends on the phase of the voltage grid, $\theta_{i}$. However, as it will be shown hereinafter, this issue does affect neither the stability nor the correct behavior of the PV inverter.

\section{EFFects of the Grid Pollution On the Three-Phase PHOTOVOLTAIC INVERTER}

\section{A. SRF-PLL}

The SRF-PLL is based on the projection of the three-phase grid voltage, $\vec{v}_{g}$, from the natural reference frame (NRF) to the synchronous reference frame (SRF). The projection is carried out by means of the Park's transformation, $T_{\text {park }}$, so that $\vec{v}_{d q}$ is obtained by means of (7). In this equation, $\hat{\theta}_{i}$ is the estimated grid voltage phase, obtained by driving $v_{q}=0$ [12]. TABLE I

EXPRESSIONS OF THE OPERATING POINT VALUES

\begin{tabular}{cc}
\hline \hline Parameter & Value \\
\hline$D_{\alpha}$ & $\sqrt{\frac{3}{2} \frac{V_{1}}{V_{P V}} \cos \left(\theta_{i}\right)}$ \\
$D_{\beta}$ & $\sqrt{\frac{3}{2} \frac{V_{1}}{V_{P V}} \sin \left(\theta_{i}\right)}$ \\
& $\sqrt{\frac{2}{3} \frac{V_{P V} I_{P V}}{V_{1}} \cos \left(\theta_{i}\right)}$ \\
$I_{\alpha}$ & $\sqrt{\frac{2}{3} \frac{V_{P V} I_{P V}}{V_{1}} \sin \left(\theta_{i}\right)}$ \\
$I_{\beta}$ & $-\frac{I_{P V}}{V_{P V}}$ \\
$k_{P V}$ & $\vec{v}_{d q}=\left[\begin{array}{l}v_{d} \\
v_{q}\end{array}\right]=T_{p a r k} \cdot \vec{v}_{g}$
\end{tabular}

Taking into account that the voltages at the PCC may contain harmonic distortion and may be unbalanced [23], (8) can be used to model the actual grid voltages. In this model, the fundamental harmonic along with the $5^{\text {th }}, 7^{\text {th }}, 11^{\text {th }}$ and $13^{\text {th }}$ harmonics have been considered. Furthermore, the effect of the unbalance has been modeled by means of the terms $(1+\beta)$ and $(1+\gamma)$. Although the model might not be realistic in some situations (e.g. it might be a purely resistive and unbalanced load and a non-linear and balanced load), it allows testing the performance of the controller and of the phase estimator in a very rough environment (i.e. positive and negative harmonics).

$\vec{v}_{g}=\left[\begin{array}{c}V_{1} \cos \left(\theta_{i}\right)-V_{5} \cos \left(5 \theta_{i}\right)+V_{7} \cos \left(7 \theta_{i}\right)-V_{11} \cos \left(11 \theta_{i}\right)+\ldots \\ (1+\beta) \cdot\left(V_{1} \cos \left(\theta_{i}-\frac{2 \pi}{3}\right)-V_{5} \cos \left(5\left(\theta_{i}-\frac{2 \pi}{3}\right)\right)+\ldots\right) \\ (1+\gamma) \cdot\left(V_{1} \cos \left(\theta_{i}+\frac{2 \pi}{3}\right)-V_{5} \cos \left(5\left(\theta_{i}+\frac{2 \pi}{3}\right)\right)+\ldots\right)\end{array}\right]$

By using (8) in (7), and taking into account that $\hat{\theta}_{i} \approx \theta_{i} \rightarrow \theta_{i}+\hat{\theta}_{i} \approx 2 \theta_{i}$, the $v_{q}$ term shown in (9) is obtained, where $E_{q}$ and $E_{p u}$ are defined in (10) and (11), respectively.

$v_{q}=E_{g}\left(\theta_{i}-\hat{\theta}_{i}\right) \cdot\left(\frac{3+\gamma+\beta}{3}\right)+E_{g} E_{p u} \cos \left(2 \theta_{i}-\phi_{p u}\right)+$
$+\sqrt{\frac{3}{2}}\left(V_{5}+V_{7}\right) \cdot \cos \left(6 \theta_{i}+\frac{\pi}{2}\right)+\sqrt{\frac{3}{2}}\left(V_{11}+V_{13}\right) \cdot \cos \left(12 \theta_{i}+\frac{\pi}{2}\right)+\ldots$ 


$$
\begin{gathered}
E_{p u}=\sqrt{\left(\frac{(\gamma-\beta)}{2 \sqrt{3}}\right)^{2}+\left(\frac{(\gamma+\beta)}{6}\right)^{2}} \\
\phi_{p u}=\tan ^{-1}\left(\frac{\sqrt{3}}{3} \frac{(\gamma+\beta)}{(\gamma-\beta)}\right)
\end{gathered}
$$

When there are neither unbalance (i.e. $\gamma=\beta=0$ ) nor harmonic distortion, (9) becomes (12). Forcing $v_{q}$ to be zero by means of the appropriated closed loop controller allows estimating the phase of the voltage grid.

$$
\hat{\theta}_{i}=\theta_{i}-\frac{v_{q}}{E_{g}} \stackrel{v_{q}=0}{\longrightarrow} \hat{\theta}_{i}=\theta_{i}
$$

However, when there are both, unbalance and harmonic distortion, the use of the same closed loop control technique to drive $v_{q}$ to zero, leads to the phase estimation equation expressed by (13), where the error due to the unbalance corresponds to the $2^{\text {nd }}$ term, and the error due to the harmonic distortion corresponds to the $3^{\text {rd }}, 4^{\text {th }}$ and consecutive terms.

$$
\begin{aligned}
& \hat{\theta}_{i}=\theta_{i}+\varepsilon_{\theta}=\theta_{i}+\frac{3}{3+\gamma+\beta} E_{p u} \cos \left(2 \theta_{i}-\phi_{p u}\right)+ \\
& +\frac{\left(V_{5}+V_{7}\right)}{V_{1}} \cdot \cos \left(6 \theta_{i}+\frac{\pi}{2}\right)+\frac{\left(V_{11}+V_{13}\right)}{V_{1}} \cdot \cos \left(12 \theta_{i}+\frac{\pi}{2}\right)+\ldots
\end{aligned}
$$

It is important pointing out that the estimated phase is used to generate the StRF currents reference signals, $\vec{i}_{S t R F}^{* s}$, in the control scheme shown in Fig. 1. Equation (14) shows the mathematical expression of the $d q / \alpha \beta$ block, where $\varepsilon_{\theta}$ is the estimation error due to the grid voltage unbalance and the THDv in the PCC. In this equation it is clearly shown that a polluted estimation results in a polluted current reference signal, thus increasing the THDi of the current generated by the inverter.

$$
\vec{i}_{\text {StRF }}^{*_{s}}=i_{d}^{*} e^{j \hat{\theta}_{i}}=i_{d}^{*} e^{j \theta_{i}+\varepsilon_{\theta}}
$$

To avoid the unbalance and the harmonic distortion to affect the estimated phase, even if the frequency of the grid voltage varies, an adaptive an inherently stable algorithm will be proposed further in this paper.

\section{B. Conventional StRF PR controller}

The PR controller is based on the internal principle mode, so that if a sinusoidal reference with frequency $\omega_{i}$ is to be tracked, a sinusoidal generator with frequency $\omega_{i}$ is to be included in the control loop [24]. In the most general case where multiple sinusoidal signals have to be tracked/rejected, (15) can be used to implement the PR, where each of the terms in the sumatory are the Laplace transfer function of each of the sinusoidal signal to be tracked/rejected (e.g. fundamental, $5^{\text {th }}$, $7^{\text {th }}, 11^{\text {th }}$ and $13^{\text {th }}$ harmonics or $\left.h=\{1,5,7,11,13\}\right)$. The $K_{P}$ term is the proportional gain, and it is added to adjust the stability of the overall control system, while $K_{R h}$ is the gain of the filter at the resonant frequency, $\omega_{R h}$.

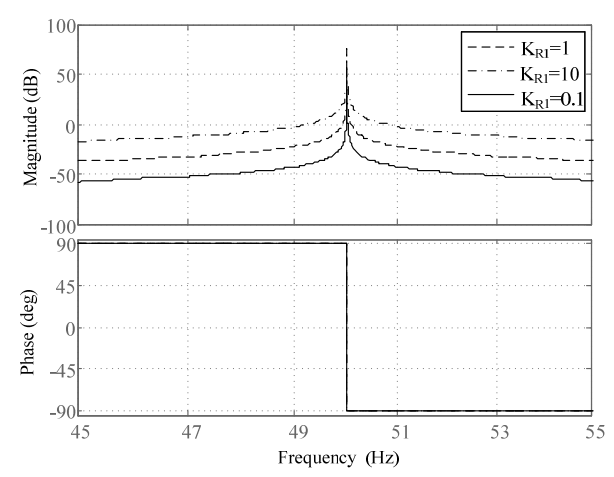

Fig. 3. Bode plot of the resonant controller.

$$
H_{P R}(s)=K_{P}+\sum_{h} K_{R h} \frac{s}{s^{2}+\omega_{R h}^{2}}
$$

The Bode plot of a PR tuned at $h=1$ (i.e. $\omega_{R I}=2 \pi 50 \mathrm{rad} / \mathrm{s}$ ) is depicted in Fig. 3, for several values of $K_{R 1}$. Obviously, similar results are obtained for each of the PRs used in the control loop. In this figure it is clearly shown that the bandwidth of the resonant controller is extremely narrow. In this regard, if a slight variation on the frequency of the reference signal occurs, the effect of the resonant controller over the controlled current will not be the one expected. This is due to the fact that the good sinusoidal tracking characteristic of the PR, can only be assured when the frequency of the reference signal perfectly matches the resonant frequency of the controller

To avoid this problem, and some other issues related with the digital implementation of the controller (e.g. it is not possible to obtain infinite gain at the resonant frequency), the alternative PR controller expressed by (16) can be used, where $B W_{R h}$ allows to choice the desired bandwidth.

$$
H_{P R}(s)=K_{P}+\sum_{h} K_{R h} \frac{B W_{R h} s}{s^{2}+B W_{R h} s+\omega_{h}{ }^{2}}
$$

However, there exists an upper limit for the chosen bandwidth if several resonant filters are used, i.e. an unstable closed loop system may be obtained as a result of a high bandwidth filters. In this regard, it is desirable to find a sinusoidal signal generator topology (i.e. a resonant filter topology), able to automatically track a variable frequency reference signal, so that a low THDi is obtained even if the inverter is connected to a polluted grid whose frequency varies.

\section{THE INHERENTLY STABLE AdAPTIVE FILTER}

As previously stated, the behavior of the conventional SRFPLL and of the PR controller is not the expected one if the voltage at the PCC is polluted and its frequency varies. This problem can be avoided by using notch filters with real-time varying resonant frequency capabilities in the SRF-PLL, and a real-time variable frequency sinusoidal generator in the output current control loop. As it will be explained next, both tasks can be accomplished by using the inherently stable adaptive 
filter based on the Schur-lattice IIR structure.

\section{A. The Schur-lattice IIR Structure}

The Schur-lattice IIR structure has been widely used in digital signal processing applications due to these important properties [25]:

i. The structure is inherently limited to realize stable and causal filters.

ii. A band-stop as well as a band-pass filter can be obtained by using the same topology.

iii. All the internal nodes are inherently scaled in the Euclidean norm. In this regard, the precision can be kept constant during the filtering process.

iv. The mapping of the poles and zeros is more precise no matter the position of the poles and zeros, because of the round-off noise accumulation in the state vector loop is inherently low.

v. Quantization limit cycles can be easily suppressed.

Property $i$. assures that the filter does not compromise the stability of the closed control loop, even if its coefficients are varied in real-time. Property ii. assures that an adaptive notch filter as well as an adaptive sinusoidal signal generator (i.e. a resonant band-pass filter), can be obtained by using the Schurlattice IIR structure. The rest of the aforementioned properties make this topology a good choice when a fixed-point digital signal processor is used. Indeed, property iv. makes this topology a very interesting choice for power electronics applications, because the sampling frequency is usually much higher than the fundamental frequency of the reference signal.

The topology of the second order IIR Schur-lattice filter is shown in Fig. 4 (a), whereas the Schur-lattice recursion is shown in Fig. 4 (b). As previously stated, this topology allows obtaining the complementary band -stop and band-pass filters expressed by (17) and (18), respectively. In both cases, the normalized center frequency, $\omega_{0}$, and the bandwidth, $B W$, can be adjusted by (19) and (20), respectively. The constant $K_{L}$ is used to set the gain of the band-pass filter. The Bode plots of both, $G(z)$ and $H(z)$, are depicted in Fig. 5, for $\theta_{1}=0 \mathrm{rad}$, $\theta_{2}=1.414 \mathrm{rad}$ and $K_{L}=1$.

$$
\begin{gathered}
G(z)=\frac{1}{2} \cdot \frac{\left(1+\sin \left(\theta_{2}\right)\right)\left(1+2 \sin \left(\theta_{1}\right) z^{-1}+z^{-2}\right)}{1+\sin \left(\theta_{1}\right)\left(1+\sin \left(\theta_{2}\right)\right) z^{-1}+\sin \left(\theta_{2}\right) z^{-2}} \\
H(z)=\frac{K_{L}}{2} \cdot \frac{\left(1-\sin \left(\theta_{2}\right)\right)\left(1-z^{-2}\right)}{1+\sin \left(\theta_{1}\right)\left(1+\sin \left(\theta_{2}\right)\right) z^{-1}+\sin \left(\theta_{2}\right) z^{-2}} \\
\omega_{0}=\theta_{1}+\frac{\pi}{2}, \quad\left|\theta_{1}\right|<\frac{\pi}{2} \\
B W=-2 \tan ^{-1}\left(\frac{\sin \left(\theta_{2}\right)-1}{\sin \left(\theta_{2}\right)+1}\right)
\end{gathered}
$$

A recursive algorithm can be used to automatically adjust in real-time the parameter $\theta_{1}$, so that the center frequency of the filters are able to track a reference signal whose frequency varies. Due to the fact that $G(z)$ as well as $H(z)$ are second order IIR filters, it is mandatory to assure that the adaptation process does not result in an unstable filter.

The stability of the Schur-lattice filter IIR structure can be tested by means of the Schur-Cohn stability test [26] applied to the function $\hat{F}_{2}(z)$. This function is the output transfer function of the $\theta_{2}$ Schur recursion depicted in Fig. 4 (b). The solution of the stability test allows affirming that the filters are stable if (21) holds true [27].

$$
\left|\sin \left(\theta_{2-k}\right)\right|<1, \quad k=0,1
$$

Obviously, (21) is always true except for the angles $\theta_{1}= \pm \pi / 2$ and $\theta_{2}= \pm \pi / 2$. However, if this condition arises, then the zeros and the poles of the filter are located at the unit circle and consequently they cancel out; moreover, the Schur recursion makes these reciprocal roots to cancel out at the output of the filter because of the same reason [25]. Taking th

at into account, the stability can be assured under all circumstances.

Due to the fact that the parameters of $G(z)$ and $H(z)$ have to be adapted in real time, it should be noted that the conclusion about stability discussed above is of a great interest, since the use of the Schur-lattice IIR structure

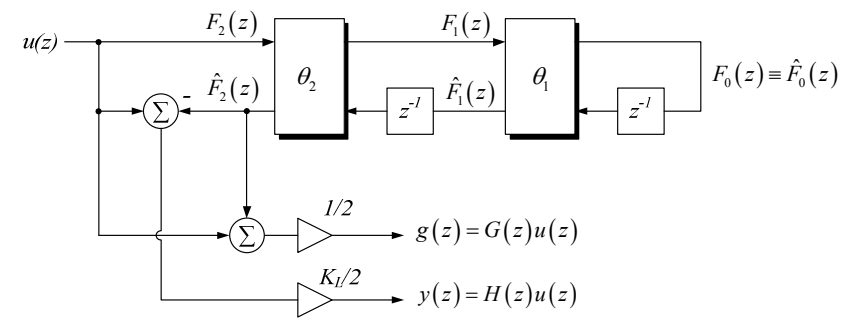

(a)

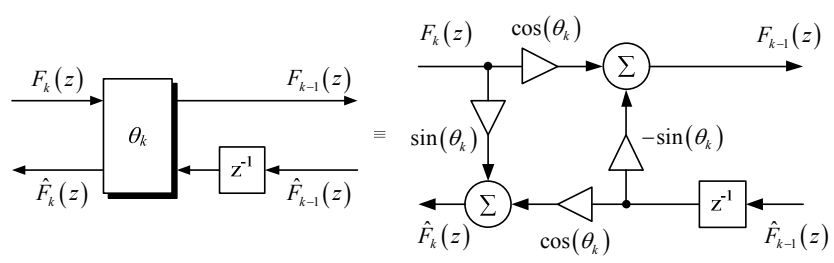

(b)

Fig. 4. (a) Second order Schur-Lattice IIR topology and (b) Schur recursion

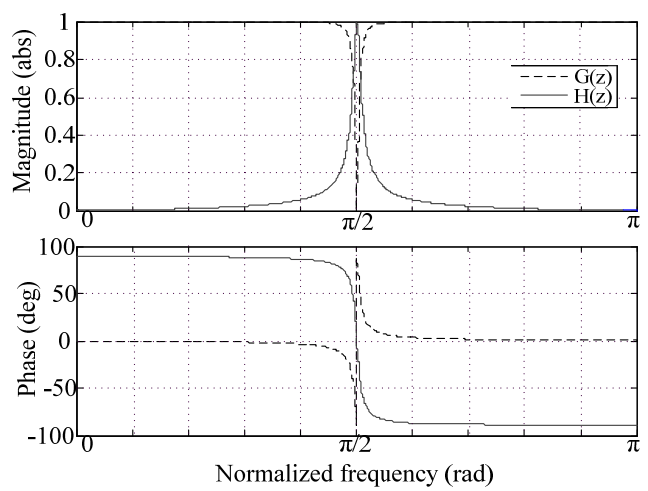

Fig. 5. Second order Schur-Lattice IIR stop-band filter, $G(z)$, and band-pass filter, $H(z)$, for $\theta_{1}=0 \mathrm{rad}, \theta_{2}=1.414 \mathrm{rad}$ and $K_{L}=1$ 
proposed in Fig. 4, provides an inherently stable IIR filter regardless of the adaptation of the filter coefficients in realtime.

\section{B. The Adaptive Algorithm}

As previously mentioned, it is possible to use a recursive algorithm to automatically adapt the coefficients of the Schur-lattice structure in real time, so that the center frequency of $G(z)$ and $H(z)$ tracks a given reference signal whose frequency may vary.

The proposed adaptive filtering technique is based on the use of a recursive algorithm to find the Wiener solution of an error surface that may be time variant (e.g. a surface dependent on the frequency of the PCC voltage). Although there are several methods that can be used to implement the recursive algorithm, the most widely used is the Least Mean Squares (LMS) algorithm [28], [29]. When this method is applied to a lattice filter, it is called Gradient Adaptive Lattice (GAL) algorithm.

The GAL applied to the second order Shur-lattice filter under study is based on the general recursive expression shown in (22), where $e(n)$ is the value of error surface at the instant $n, \mu$ is the learning rate of the adaptive filter, and $\nabla \theta_{1}(n)$ is a filtered regressor [25].

$$
\theta_{1}(n+1)=\theta_{1}(n)+\mu e(n) \nabla \theta_{1}(n)
$$

The main objective of the adaptive process is to automatically obtain the parameter $\theta_{1}$ that allows finding a minimum on the time varying error surface. Taking this into account, it is of a paramount importance to find an error surface which is related to the frequency of the reference signal. Indeed, finding a minimum on that error surface is equivalent to find the frequency of the reference signal. If the frequency of the reference signal varies (i.e. the error surface varies), the recursive algorithm will find the new parameter $\theta_{l}$ that corresponds to a minimum in the new error surface (i.e. the filter will be automatically tuned at the new frequency).

It can be proven that the GAL algorithm that allows adapting the value of $\theta_{1}$ in real time is expressed by (23) [25].

$$
\theta_{1}(n+1)=\theta_{1}(n)-\mu y(n) \nabla \theta_{1}(n)
$$

This algorithm is obtained by making the output of the filter, $y(n)$, to be the error surface in (22). This solution implies that the GAL Schur-lattice IIR filter does not need a reference to adaptively tune its center frequency [27]. As it will be shown further, this property is of a great importance when filtering out the SRF-PLL.

In this paper, the GAL has been applied to the Schur-lattice IIR band-stop filter, $G(z)$, so that an adaptive band-stop filter is obtained. The adaptation process of the band-pass filter, $H(z)$, will be described later on. The proposed adaptive bandstop filter, including the computing of the filtered regressor, $\nabla \theta_{1}(n)$, is shown in Fig. 6. In this figure, $u(n)$ is the input signal expressed by (24), where $\{\zeta(\cdot)\}$ is an error signal statistically independent of $u(n), p_{1}$ is the amplitude of the sinusoidal signal of frequency $\omega_{1}$, and $T_{s}$ is the sampling period of the discretized system.

$$
u(n)=p_{1} \sin \left(\omega_{1} T_{s} n\right)+\zeta(n)
$$

The GAL algorithm automatically adapts the parameter $\theta_{1}$ in real time, so that $\theta_{1}=\omega_{1}+\frac{\pi}{2}$, no matter the value of $\omega_{1}$ or its time varying behavior.

Although the aforementioned GAL Schur-lattice filter can be directly implemented into a digital signal processor, it is possible to obtain the simplified algorithm shown in Table II [25]. This algorithm behaves like the original one, and avoids using the two extra Schur recursions involved in the computation of the original filtered regressors.

TABLE II

SiMPLIFIED GAL ALGORITHM APPLIED TO THE SCHUR-LATTICE IIR NOTCH FILTER

$\frac{\text { Filter Parameters Computing }}{\left[\begin{array}{l}g_{1}(n) \\ w_{1}(n)\end{array}\right]=\left[\begin{array}{cc}\cos \left(\theta_{2}\right) & -\sin \left(\theta_{2}\right) \\ \sin \left(\theta_{2}\right) & \cos \left(\theta_{2}\right)\end{array}\right]\left[\begin{array}{c}u(n) \\ x_{2}(n-1)\end{array}\right]}$

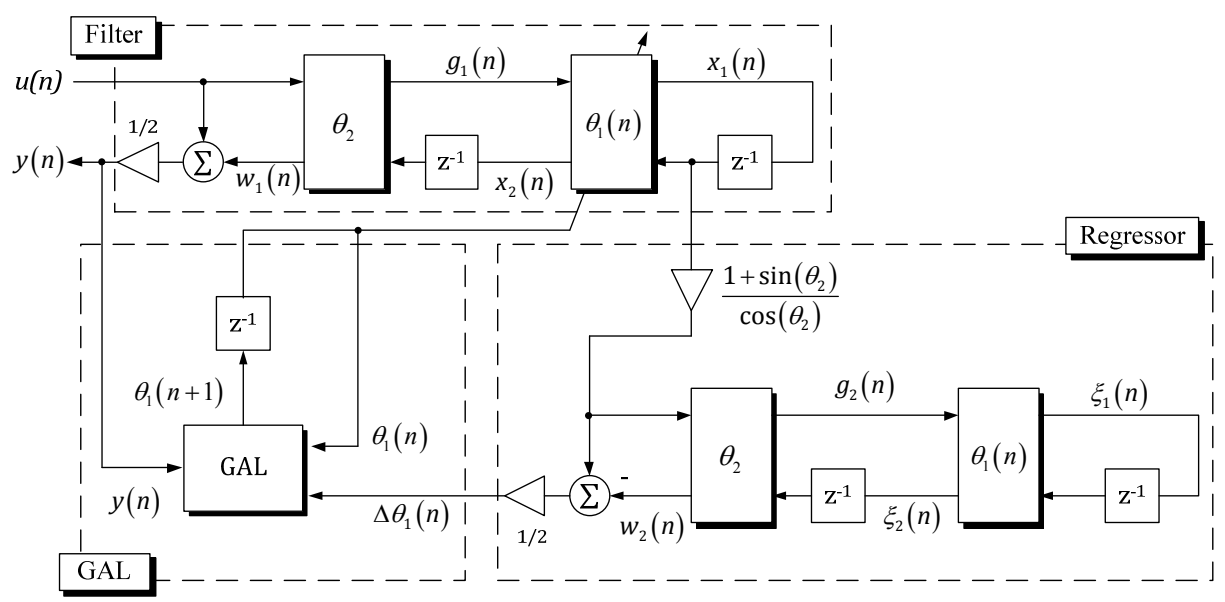

Fig. 6. A second order GAL Schur-lattice IIR band-stop filter. 


$$
\begin{gathered}
{\left[\begin{array}{l}
x_{1}(n) \\
x_{2}(n)
\end{array}\right]=\left[\begin{array}{cc}
\cos \left(\theta_{1}(n)\right) & -\sin \left(\theta_{1}(n)\right) \\
\sin \left(\theta_{1}(n)\right) & \cos \left(\theta_{1}(n)\right)
\end{array}\right]\left[\begin{array}{c}
g_{1}(n) \\
x_{1}(n-1)
\end{array}\right]} \\
y(n)=\frac{1}{2}\left[u(n)+w_{1}(n)\right]
\end{gathered}
$$

Filter Parameters Adaptation

$$
\theta_{1}(n+1)=\theta_{1}(n)-\mu y(n) x_{1}(n-1)
$$

\section{The Proposed AdAPtive Control System}

Fig. 7 shows the proposed adaptive control system. On the one hand, the PR controller has been substituted by the Schurlattice band-stop filter. The proposed controller is described further on this paper, and it is called the Proportional+Lattice (PL) controller. On the other hand, the $v_{q}$ term of the SRF-PLL has been filtered out by means of the band-stop Schur-lattice filter. The adaptively filtered SRF-PLL is called the Adaptive Lattice SRF-PLL (ALSRF-PLL).

\section{A. The Adaptive Lattice SRF-PLL (ALSRF-PLL)}

The ALSRF-PLL has been succesfully used before in a three-phase grid connected inverter [27]. Its basic block diagram is shown in Fig. 8 (a). Three adaptive band-stop filters are used to reject the unbalance and the $5^{\text {th }}, 7^{\text {th }}, 11^{\text {th }}$ and $13^{\text {th }}$ harmonics in the NRF. Yet, those filters are pre-tuned at the $2^{\text {nd }}, 6^{\text {th }}$ and $12^{\text {th }}$ harmonics in the SRF. However, the tuning frequency will automatically vary if a variation on the grid frequency occurs, so that the grid disturbances are effectively rejected no matter the grid frequency.

In order to study the stability and the disturbance rejection capability of the ALSRF-PLL, the linearized small-signal model depicted in Fig. 8 (b) has been used.

On the one hand, $H_{P I}(z)$ is the digital PI controller described by (25), $\operatorname{Int}(z)$ is a discrete integrator and $E_{g}(z)$ is the small signal gain of the SRF-PLL defined by (26) where $V_{l}$ is the amplitude of the grid voltage in the NRF, $\beta_{v}$ is the sensing gain and $H_{A A}(z)$ is a second order anti-aliasing filter tuned at half the sampling frequency. On the other hand, $G_{2}(z), G_{6}(z)$ and $G_{12}(z)$ are the GAL Schur-lattice band-stop filters initially tuned at the $2^{\text {nd }}, 6^{\text {th }}$ and $12^{\text {th }}$ harmonics, respectively. Finally, the open loop gain of the ALSRF-PLL, $T_{P L L}(z)$, and the disturbance rejection transfer function, $G_{\theta_{-} d}(z)$, are described by (27) and (28), respectively.

$$
\begin{gathered}
H_{P I}(z)=K_{P}\left(1+K_{i} \frac{T_{S}}{2} \cdot \frac{\left(1+z^{-1}\right)}{\left(1-z^{-1}\right)}\right) \\
E_{g}(z)=-\sqrt{\frac{3}{2}} V_{1} \cdot \beta_{v} \cdot H_{A A}(z)
\end{gathered}
$$

$$
\begin{gathered}
T_{P L L}(z)=E_{g}(z) \cdot H_{P I}(z) \cdot \operatorname{Int}(z) \cdot G_{2}(z) \cdot G_{6}(z) \cdot G_{12}(z)(27) \\
G_{\theta_{-} d}(z)=\frac{1}{E_{g}(z)} \frac{T_{P L L}(z)}{1+T_{P L L}(z)}
\end{gathered}
$$

By taking into account the polluted electric grid shown in Table III, the nominal parameters of the ALSRF-PLL shown in Table IV have been chosen, where $T_{s}$ is the sampling period. Besides, the Bode plot of (27) and (28) are depicted in Fig. 9 (a) and (b), respectively.

In Fig. 9 (a) it is shown that the stability of the ALSRFPLL is assured for the nominal grid frequency (i.e. $P M=75.3^{\circ}$ at $f_{c}=44 \mathrm{~Hz}$ and $G M=54.5 \mathrm{~dB}$ at $f_{c}=8060 \mathrm{~Hz}$ ), as well as for the

TABLE III

PARAMETERS OF THE POLLUTED ELECTRIC GRID

\begin{tabular}{cc}
\hline \hline Parameter & Value \\
\hline$V_{1}$ & $188 \mathrm{~V}$ \\
$f_{i}$ & $50 \mathrm{~Hz}$ \\
$V_{5}=0.1 V_{1}$ & $18.8 \mathrm{~V}$ \\
$V_{7}=0.07 V_{1}$ & $13.2 \mathrm{~V}$ \\
$V_{11}=0.05 V_{1}$ & $8.5 \mathrm{~V}$ \\
$V_{13}=0.04 V_{1}$ & $7.2 \mathrm{~V}$ \\
$\beta$ & -0.1 \\
$\gamma$ & 0.3
\end{tabular}

TABLE IV

PARAMETERS OF THE ALSRF-PLL

\begin{tabular}{cc}
\hline \hline Parameter & Value \\
\hline$T_{S}$ & $62.5 \mu \mathrm{s}$ \\
$\theta_{1 \_2(\text { nominal })}$ & -1.531526418 \\
$\omega_{0 \_} 2$ & $2 \pi 100 \mathrm{rad} / \mathrm{s}$ \\
$\mu \_2$ & 0.0001
\end{tabular}

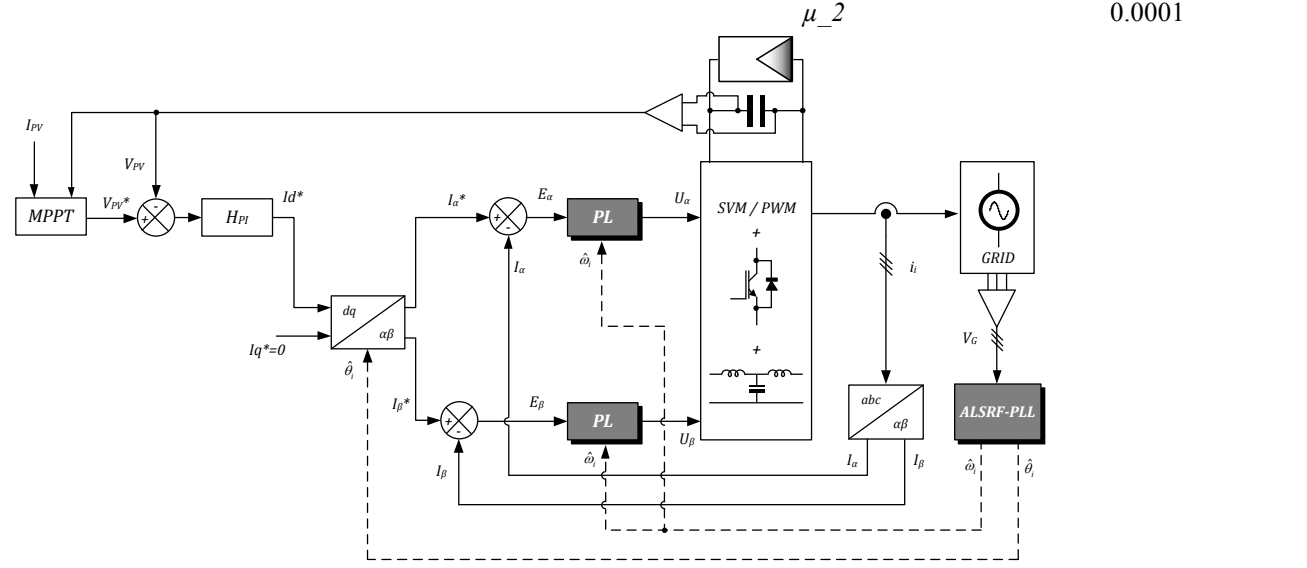

Fig. 7. Simplified schematic of the adaptive control strategy. 


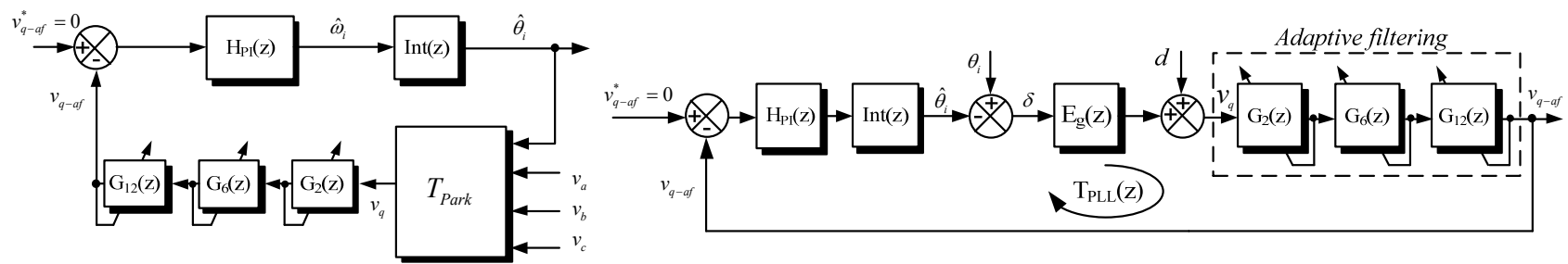

(a)

(b)

Fig. 8. (a) Basic block diagram and (b) small signal block diagram of an ALSRF-PLL.

$\begin{array}{cc}\theta_{1} 6 \text { (nominal) } & -1.452986602 \\ \omega_{0} \sigma & 2 \pi 300 \mathrm{rad} / \mathrm{s} \\ \mu \_6 & 0.0001 \\ \theta_{1} 12 \text { (nominal) } & -1.335176877 \\ \omega_{0 \_} 12 & 2 \pi 600 \mathrm{rad} / \mathrm{s} \\ \mu_{-} 12 & 0.01 \\ B W_{-} 2=B W \_6=B W_{-} 12 & 20 \mathrm{~Hz} \\ \theta_{2} 2=\theta_{2 \_} 6=\theta_{2} 12 & 1.445132620 \\ \beta_{V} & 2.5 \cdot 10^{-3} \\ K_{p} & 477.46 \\ K_{i} & 31.42\end{array}$

minimum and the maximum grid frequencies considered (i.e. $45 \mathrm{~Hz}$ and $55 \mathrm{~Hz}$, respectively). Furhtermore, in Fig. 9 (b) is clearly visible the effect of the adaptive Schur-lattice bandstop filters in rejecting the grid disturbances, no matter the variation on their frequency. Indeed, the disturbance rejection is kept almost constant no matter the frequency of the grid voltage,i.e.

$\left|G_{\theta_{-} d}\left(e^{j 2 \pi f}\right)\right| \approx-50 d B, f=\left\{2 f_{i}, 6 f_{i}, 12 f_{i}: 45<f_{i}<55\right\} \mathrm{Hz}$.

On the contrary, the disturbance attenuation without the adapive filtering (i.e. NF legend) is $\left|G_{\theta_{-} d}\left(e^{j 2 \pi f}\right)\right| \approx 0 d B, f=\left\{2 f_{i}: f_{i}=45\right\} H z$. Therefore, no attenuation of the unbalance will exist in the worst case considered, i.e. $f_{i}=45 \mathrm{~Hz}$, if the conventional SRF-PLL is used.

\section{B. The Proportional + Lattice $(P L)$ controller}

As previously stated, a variable frequency sinusoidal generator (i.e. a variable frequency band-pass or resonant controller) may be included in the closed loop control of the inverter output current to properly track a variable frequency reference signal. The aforementioned adaptive band-pass filter has been chosen because of its stability and robust numeric properties. This filter along with a proportional gain form the PL controller, which is described by (29), where $K_{P L}$ is the proportional gain, $K_{L h}$ is the gain of each of the $h$ filters, $\theta_{2 h}$ is a constant that allows to adjust the quality factor, and $\theta_{1 h}$ is the Schur recursion parameter that is adjusted in real-time to adapt the center frequency of the filter.

$H_{P L}(z)=K_{P L}+\sum_{h=1,5,7,11,13} \frac{K_{L h}}{2} \cdot \frac{\left(1-\sin \left(\theta_{2 h}\right)\right)\left(1-z^{-2}\right)}{1+\sin \left(\theta_{1 h}\right)\left(1+\sin \left(\theta_{2 h}\right)\right) z^{-1}+\sin \left(\theta_{2 h}\right) z^{-2}}$

To adapt the center frequency of $H_{P L}(z)$, the frequency estimated by the ALSRF-PLL, $\hat{f}_{i}$, can be used. It should be noticed that $\hat{f}_{i}$ is pre-multiplied by the harmonic number $h$ according to the corresponding filter, $H_{L h}(\mathrm{z})$. In this paper, $h$ has been chosen to be $h=\{1,5,7,11,13\}$. However, a different set of harmonics can be tracked/rejected, by changing $h$ and adding or removing as many Schur-lattice filters as

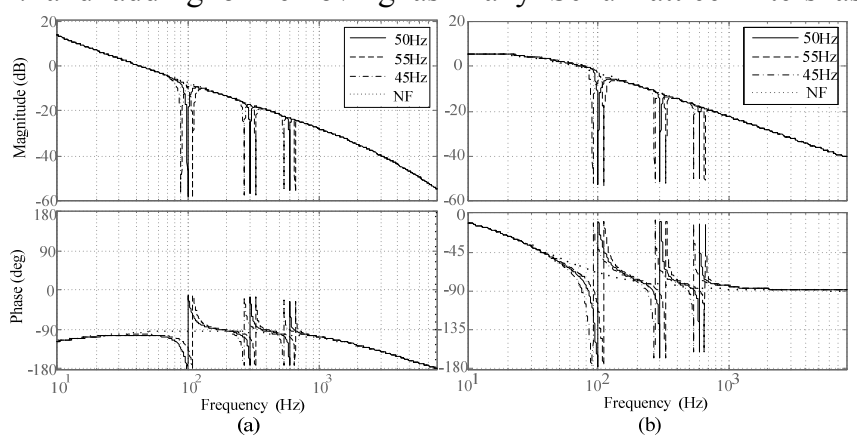

Fig. 9. Bode plots of (a) the open loop gain and (b) the attenuation of the disturbances contained in the $v_{q}$ signal.

required.

It is important pointing out that the frequency estimated by a conventional SRF-PLL cannot be used to adapt the center frequency of the proposed PL, if the grid voltage is polluted. Indeed, using an estimated frequency that contains harmonics, will make the PL to swing around the center frequency because of the ripple. The use of the ALSRF-PLL, though, assures a ripple free estimated frequency. Furthermore, as the PL is inherently stable, the adaptation process will not compromise the stability of the current control loop.

The block diagram of the proposed PL controller is depicted in Fig. 10 (a), where each of the Schur-lattice filters, $H_{L h}(\mathrm{z})$, are implemented by means of the band-pass Schurlattice structure shown in Fig. 10 (c). The frequency response of the PL controller is plotted in Fig. 10 (b) for $f_{i}=50 \mathrm{~Hz}$ and $f_{i}=55 \mathrm{~Hz}$. As expected, the gain of the controller at each harmonic is the same no matter the frequency of the grid voltage. 
The design of the controllers can be carried out by taking into account the linearized small-signal models of the inverter shown in Fig. 11. On the one hand, Fig. 11 (a) models the closed loop control of the PV panel output voltage. On the other hand, Fig. 11 (b) and Fig. 11 (c) model the closed loop control of the inverter output current projected in the StRF.

Due to the fact that the PV output voltage is a DC magnitude, the conventional PI described by (30) has been chosen to control it. Furthermore, the proposed PL controller has been used in the current control loops.

$$
H_{P I}(z)=K_{P}\left(1+K_{i} \frac{T_{S}}{2} \cdot \frac{\left(1+z^{-1}\right)}{\left(1-z^{-1}\right)}\right)
$$

The open loop gain of each of the control loops shown in Fig. 11 are described by (31), (32) and (33), where the smallsignal transfer functions $\tilde{v}_{P V} / \tilde{i}_{\alpha}(z), \tilde{i}_{\alpha} / \tilde{d}_{\alpha}(z), \tilde{i}_{\beta} / \tilde{d}_{\beta}(z)$ have been obtained by means of the state space model described in Section II. The parameters $\beta_{v}$ and $\beta_{i}$ are the sensing gains of the PV output voltage and of the inverter output current, respectively, $H_{A A}(z)$ is the transfer function of a second order anti-aliasing filter and $H_{L P}(z)$ is a second order low-pass filter. $H_{L P}(z)$ is designed to attenuate the lowfrequency harmonics that will appear at the DC-link when the grid voltage is unbalanced. The open loop gain plots have been used to design the controllers so that the stability of the inverter is assured.

$$
\begin{gathered}
T_{V}^{P L}(z)=H_{P I}(z) \cdot \frac{\beta_{v}}{\beta_{i}} \cdot \frac{\tilde{v}_{P V}}{\tilde{i}_{\alpha}}(z) \cdot H_{L P}(z) \\
T_{i \alpha}^{P L}(z)=H_{P L}(z) \cdot H_{P W M}(z) \cdot \frac{\tilde{i}_{\alpha}}{\tilde{d}_{\alpha}}(z) \cdot \beta_{i} \cdot H_{A A}(z) \\
T_{i \beta}^{P L}(z)=H_{P L}(z) \cdot H_{P W M}(z) \cdot \frac{\tilde{i}_{\beta}}{\tilde{d}_{\beta}}(z) \cdot \beta_{i} \cdot H_{A A}(z)
\end{gathered}
$$

The $10 \mathrm{~kW}$ PV inverter used to test the proposed adaptive control system is characterized by the parameters' values shown in Table V. Moreover, the operating point is shown in Table VI. These values have been chosen so that the PV inverter works at the maximum power point. Since the operation point of the inverter in the StRF depends on the phase of the grid voltage, $\theta_{i}$, several values for this parameter have been considered.

The tuning of the controllers' parameters has been performed by using the frequency domain loop-shaping technique. The obtained controllers' parameters are shown in Table VII. The Bode plots of the open-loop gains, $T_{V}^{P L}(z)$ and $T_{i \alpha}^{P L}(z)$, are depicted in Fig. 12 (a) and Fig.12 (b), respectively. In those plots, the grid frequency has been chosen to be $f_{i}=50 \mathrm{~Hz}$. Moreover, the operating point values shown in Table VI have been considered, so that a set of openloop gains have been plotted. By carefully examining both figures, it is possible to affirm that the variation of the operating point does affect the stability neither of the PV voltage control loop nor of the inverter current control loop.

The phase and the gain margins of each of the closed loops are shown in Table VIII for the nominal, minimum and maximum grid frequency considered, i.e. $50 \mathrm{~Hz}, 45 \mathrm{~Hz}$ and $55 \mathrm{~Hz}$, respectively. The results allow affirming that the inverter is stable over the entire range of the grid frequency variation considered (i.e. $45 \mathrm{~Hz} \sim 55 \mathrm{~Hz}$ ).

The Bode plot of the $\alpha$ channel reference current to error transfer function described by (34), is depicted in Fig. 13 for $f_{i}=\{45,50,55\} H z$. In this figure it is clearly shown that the tracking error is zero no matter the frequency of the reference.

$$
G_{e}^{P L}(z)=\frac{\tilde{e}_{\alpha}}{\tilde{i}_{\alpha}^{*}}(z)=\beta_{i} \cdot H_{A A} \cdot\left(\frac{1}{1+T_{i \alpha}^{P L}(z)}\right)
$$

TABLE V

PARAMETERS OF THE PV INVERTER

\begin{tabular}{cc}
\hline \hline Parameter & Value \\
\hline$C_{P V}$ & $2.04 \mathrm{mF}$ \\
$\beta_{V}$ & $2 \cdot 10^{-3}$ \\
$\beta_{i}$ & $31 \cdot 10^{-3}$ \\
$f_{S W}$ & $8000 \mathrm{~Hz}$ \\
$f_{S}$ & $16000 \mathrm{~Hz}$ \\
$T_{S}$ & $6.25 \cdot 10^{-5} \mathrm{~s}$ \\
$L_{g}$ & $86 \mu \mathrm{H}$ \\
$R_{g}$ & $36.7 \mathrm{mH}$ \\
$L_{i}$ & $1.6 \mathrm{mH}$ \\
$R_{i}$ & $16 \mathrm{~m} \Omega$
\end{tabular}
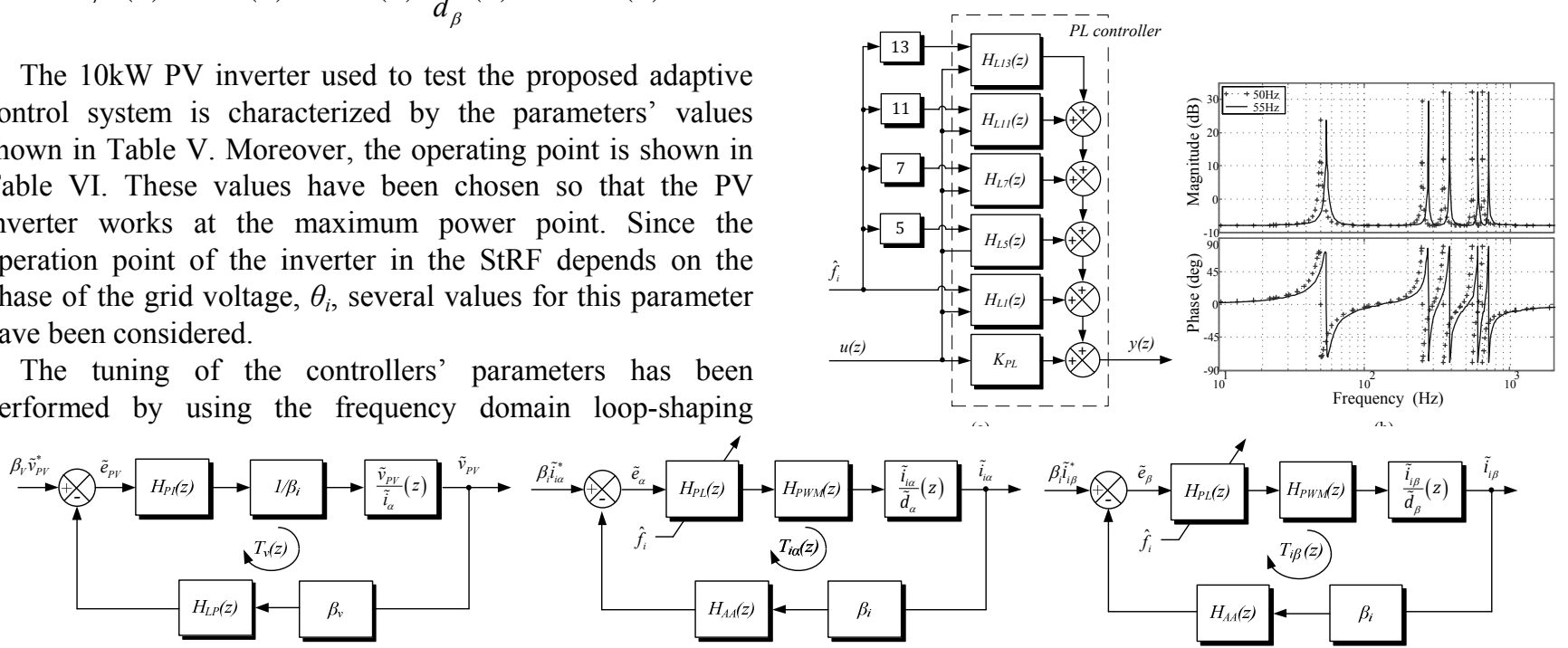

(a)

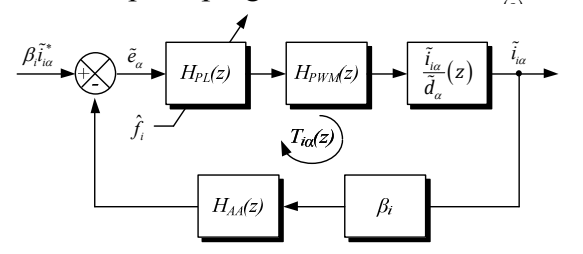

(b)

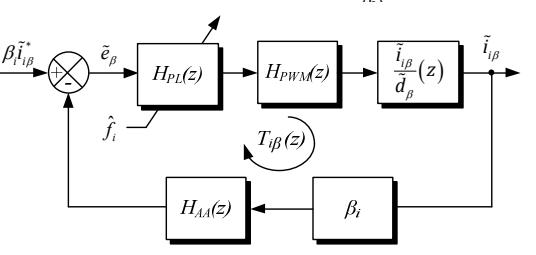

(c)

nt

Fig. 11. Block diagram of the discretized (a) PV array output voltage control, (b) $\alpha$ channel current control and (c) $\beta$ channel current control. 


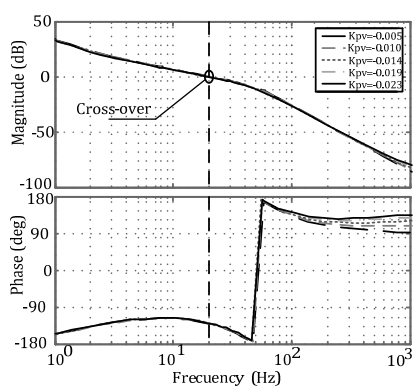

(a)

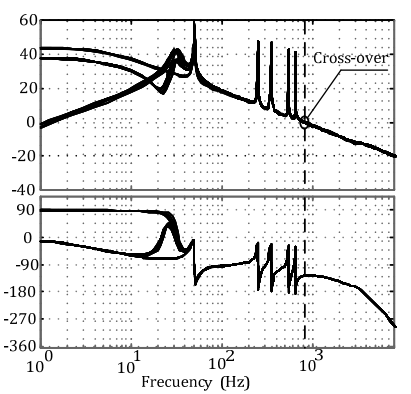

(b)
Fig. 12. Open-loop gain of the (a) PV voltage control loop and (b) $\alpha$ channel current control loop.

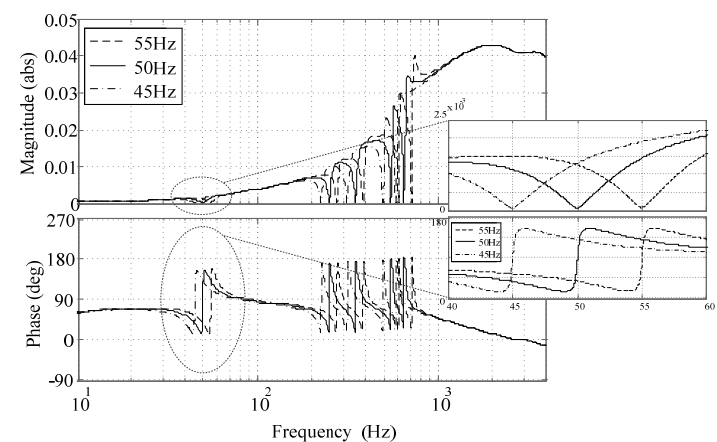

Fig. 13. Bode plot of the $\alpha$ channel output-current-reference-to-error transfer function.

$$
\begin{array}{ll}
C_{f} & 30 \mu \mathrm{F} \\
R_{d} & 0.5 \Omega
\end{array}
$$

TABLE VI

OPERATING POINT VALUES OF THE PV INVERTER

\begin{tabular}{|c|c|c|}
\hline Parameter & \multicolumn{2}{|c|}{ Value } \\
\hline$V_{P V(M P P)}$ & \multicolumn{2}{|c|}{$598,621,644,644,654$} $\mathrm{~V}$ \\
\hline$I_{P V(M P P)}$ & \multicolumn{2}{|c|}{$3,6,9,12,15$} $\mathrm{~A}$ \\
\hline$k_{P V(M P P)}$ & \multicolumn{2}{|c|}{$-10^{-3} \cdot\{5,10,14,19,23\} \mathrm{A} / \mathrm{V}$} \\
\hline$V_{g}$ & \multicolumn{2}{|c|}{$\sqrt{ }(2 / 3) \cdot 230 \mathrm{~V}$} \\
\hline$\theta_{i}$ & \multicolumn{2}{|c|}{$0, \pi / 4, \pi / 2,3 \pi / 4, \pi, 5 \pi / 4,3 \pi / 2,7 \pi / 4,2 \pi$} $\mathrm{rac}$ \\
\hline \multicolumn{3}{|c|}{ TABLE VII } \\
\hline \multicolumn{3}{|c|}{ PARAMETERS OF THE CONTROLLERS } \\
\hline \multicolumn{2}{|r|}{ Parameter } & Value \\
\hline \multicolumn{2}{|r|}{$K_{P}$} & -11.14 \\
\hline \multicolumn{2}{|r|}{$K_{I}$} & 12.57 \\
\hline \multicolumn{2}{|r|}{$K_{P L}$} & 0.42 \\
\hline \multicolumn{2}{|r|}{$K_{L 1}$} & 15 \\
\hline \multicolumn{2}{|r|}{$K_{L 5}$} & 30 \\
\hline \multicolumn{2}{|r|}{$K_{L 7}$} & 40 \\
\hline \multicolumn{2}{|r|}{$K_{L 11}$} & 40 \\
\hline \multicolumn{2}{|r|}{$K_{L 13}$} & 40 \\
\hline \multicolumn{2}{|r|}{$\theta_{11}($ nominal $)$} & $-0.49375 \pi \mathrm{rad}$ \\
\hline \multicolumn{2}{|r|}{$\theta_{15}($ nominal $)$} & $-0.46875 \pi \mathrm{rad}$ \\
\hline \multicolumn{2}{|r|}{$\theta_{17}($ nominal $)$} & $-0.45625 \pi \mathrm{rad}$ \\
\hline \multicolumn{2}{|r|}{$\theta_{111}($ nominal) } & $-0.43125 \pi \mathrm{rad}$ \\
\hline \multicolumn{2}{|c|}{$\theta_{113}($ nominal $)$} & $-0.41875 \pi \mathrm{rad}$ \\
\hline \multicolumn{2}{|c|}{$\theta_{21}=\theta_{25}=\theta_{27}=\theta_{211}=\theta_{213}$} & $0.495 \pi \mathrm{rad}$ \\
\hline
\end{tabular}

TABLE VIII

STABILITY CRITERIA

\begin{tabular}{l|ccc}
\hline \hline \multirow{2}{*}{ Parameter } & \multicolumn{3}{|c}{ Value } \\
\cline { 2 - 4 } & $45 \mathrm{~Hz}$ & $50 \mathrm{~Hz}$ & $60 \mathrm{~Hz}$ \\
\hline$T_{i \alpha}(z) P M-f_{c}$ & $57.4^{\circ}-820 \mathrm{~Hz}$ & $55.6^{\circ}-826 \mathrm{~Hz}$ & $52.6^{\circ}-836 \mathrm{~Hz}$ \\
$T_{i \alpha}(z) G M-f$ & $12.5 \mathrm{~dB}-3720 \mathrm{~Hz}$ & $12.5 \mathrm{~dB}-3720 \mathrm{~Hz}$ & $12.5 \mathrm{~dB}-3720 \mathrm{~Hz}$ \\
$T_{V}(z) P M-f_{c}$ & & $52.4^{\circ}-19.8 \mathrm{~Hz}$ & \\
$T_{V}(z) G M-f$ & & $11.5 \mathrm{~dB}-51.5 \mathrm{~Hz}$ &
\end{tabular}

\section{EXPERIMENTAL RESULtS}

The proposed control strategy has been experimentally tested by means of a set-up composed of a commercial three-phase 20KW inverter (SEMIKRON SKS 35F B6U+E1CIF+B6CI $21 \mathrm{~V} 12$ ) controlled by means of a fixed point DSP (TEXAS INSTRUMENTS TMS320F2812), a $40 \mathrm{~kW}$ DC power supply capable of emulating a PV array I-V curve (AMREL SPS-800-54-D013) and a 12kVA AC power source (Pacific Power 360-AMX). The inverter has been configured so that the maximum power is extracted from the emulated PV panel (i.e. $V_{P V}=654 V$ and $I_{P V}=15 A$ ). The real time data has been read from the DSP by using the RTDX core; MATLAB has been used to process and to plot the collected data.

The correct behavior of the ALSRF-PLL working on a polluted and frequency varying voltage grid is shown in Fig. 14. This figure shows the estimated frequency by the ALSRFPLL (grey plot) along with the estimated frequency by the conventional SRF-PLL (black plot), when the voltage is the nominal one, i.e. $50 \mathrm{~Hz}$ and has no unbalance or harmonic distortion $(t=0 s)$, when the voltage is unbalanced and distorted $(t \approx 9.5 s)$, when the frequency of the polluted grid abruptly varies from $50 \mathrm{~Hz}$ to $55 \mathrm{~Hz}(t \approx 11.5 \mathrm{~s})$ and when the voltage unbalance and the voltage distortion disappear, and the frequency get back to $50 \mathrm{~Hz}(t \approx 13.5 s)$. As expected, the results show that the estimated frequency is ripple free when the ALSRF-PLL is used. This estimated frequency will be used to adapt the center frequency of the PL controllers in real time. Moreover, it is worth pointing out that the transient response and the convergence of the adaptive filter are adjusted by means of the $\mu$ parameter [27].

In order to compare the behavior of the conventional control technique with the proposed one, the THDv of the grid voltage at the PCC has been programmed to be $11.5 \%$, with a $20 \%$ of voltage unbalance. The phase-to-phase voltages at the inverter side along with the current generated by the inverter at one phase have been measured, when the grid frequency is

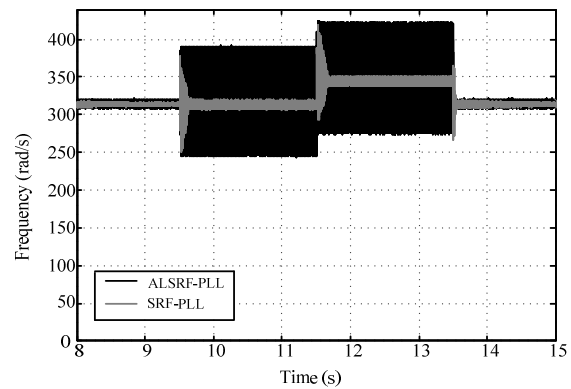

Fig. 14. Frequency estimation of the ALSRF-PLL (black) and of the conventional SRF-PLL (grey), when the grid frequency of a unbalanced and distorted grid abruptly varies. 


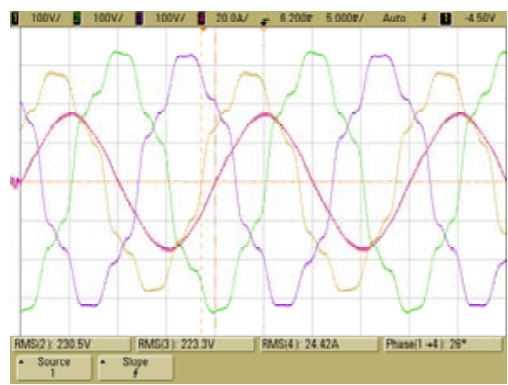

(a)

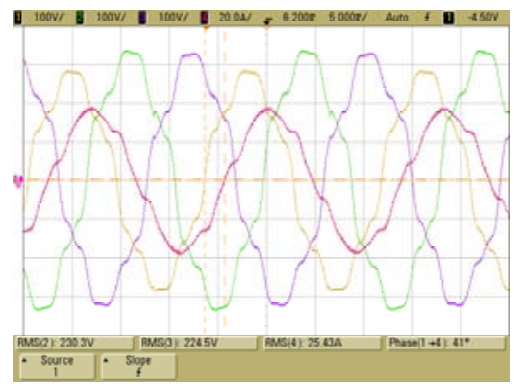

(b)

Fig. 15. Grid voltages and inverter current, $i_{i}$, steady-state time response of the SRF-PLL + PR with (a) a $50 \mathrm{~Hz}$ and (b) a $55 \mathrm{~Hz}$ distorted and unbalanced voltage grid.

$50 \mathrm{~Hz}$, and $55 \mathrm{~Hz}$, for the conventional control technique and for the proposed one.

In Fig. 15 (a) it is shown the inverter current when the SRF-PLL+PR control strategy is used in a $50 \mathrm{~Hz}$ grid. The correct performance of this control strategy can be noticed. However, it is clearly shown in Fig. 15 (b) that the SRF-PLL+PR does not perform well when the grid frequency is other than the nominal one (i.e. the frequency is varied from $50 \mathrm{~Hz}$ to $55 \mathrm{~Hz}$ ). It should be noted that the $30^{\circ}$ phase shift between the measured current and voltage waveforms is due to the measuring of the phase-to-phase voltage along with the line current.

The steady-state operation of the ALSRF-PLL+PL working in a $50 \mathrm{~Hz}$ grid voltage is depicted in Fig. 17 (a). The normal operation of the proposed control scheme is even better than the conventional one, because the estimated frequency and phase of the ALSRF-PLL contain less ripple than those of the conventional SRF-PLL. However, the better performance of the ALSRF-PLL+PL becomes much more obvious in Fig. 17 (b), where a $55 \mathrm{~Hz}$ grid frequency has been used. Apparently,

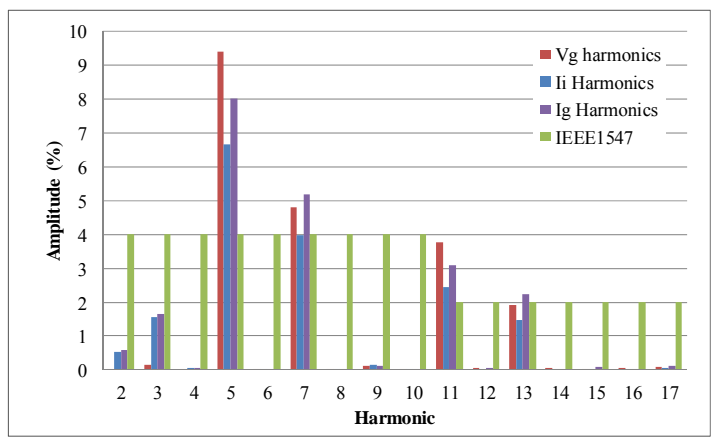

Fig. 16. Harmonic distortion of the inverter generated current $\left(i_{i}\right)$ and of the grid injected current $\left(i_{g}\right)$ in a polluted $55 \mathrm{~Hz}$ grid voltage, $v_{g}$, when using the SRF-PLL + PR.

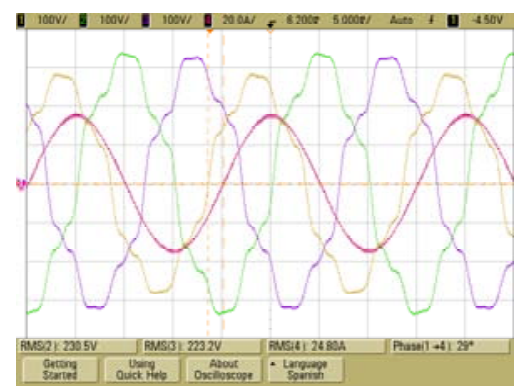

(a)

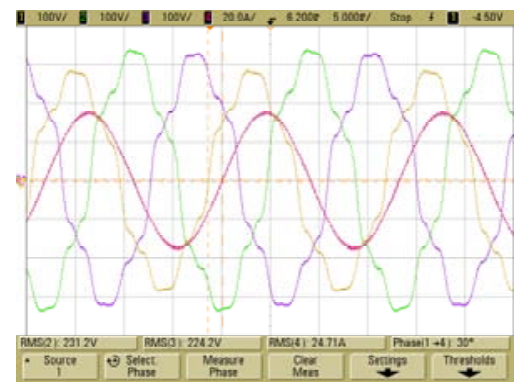

(b)

Fig. 17. Grid voltages and inverter current, $i_{i}$, steady-state time response of the ALSRF-PLL + PL with (a) a $50 \mathrm{~Hz}$ and (b) a $55 \mathrm{~Hz}$ distorted and unbalance voltage grid.

no noticeable harmonic distortion is present in the controlled current.

The THDi of the inverter generated current, $i_{i}$, and of the grid current, $i_{g}$, along with the PF have been measured by means of the electric power analyzer VOLTECH PM6000, when the grid frequency is not the nominal one (i.e. $55 \mathrm{~Hz}$ ). The test has been carried out by using both, the SRF-PLL+PR and the proposed ALSRF-PLL+PL control schemes. The results of the measurements are shown in Table IX.

The improvement of the proposed method is clearly noticeable, as a reduction from $7.1 \%$ to $0.8 \%$ in the THDi of the controlled current $\left(i_{i}\right)$, and from $8.5 \%$ to $4 \%$ in the THDi TABLE IX

QUALITY OF THE INVERTER GENERATED CURRENT AND OF THE GRID CURRENT AT $55 \mathrm{~Hz}$

\begin{tabular}{c|c|c|c|c}
\hline \hline \multirow{2}{*}{} & \multicolumn{2}{|c|}{$i_{i}$} & \multicolumn{2}{c}{$i_{g}$} \\
\cline { 2 - 5 } & $\begin{array}{c}\text { SRF-PLL } \\
+P R\end{array}$ & $\begin{array}{c}\text { ALSRF-PLL } \\
+P L\end{array}$ & $\begin{array}{c}\text { SRF-PLL } \\
+P R\end{array}$ & $\begin{array}{c}\text { ALSRF-PLL } \\
+P L\end{array}$ \\
\hline THDi & $7.102211 \%$ & $0.8060311 \%$ & $8.472592 \%$ & $4.040348 \%$
\end{tabular}

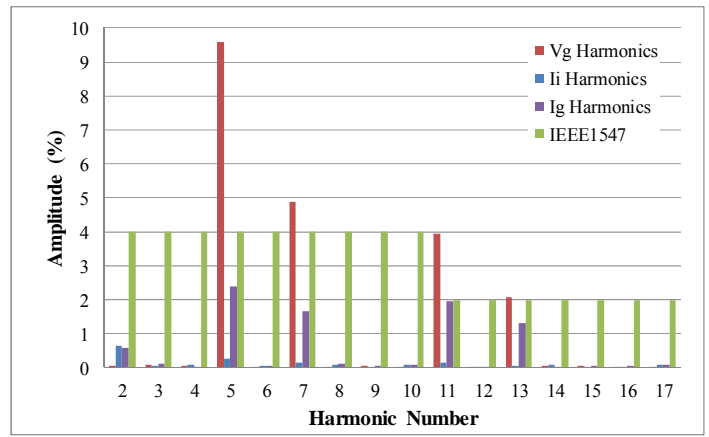

Fig. 18 Harmonic distortion of the inverter generated current $\left(i_{i}\right)$ and of the grid injected current $\left(i_{g}\right)$ in a polluted $55 \mathrm{~Hz}$ grid voltage, $v_{g}$, when using the ALSRF-PLL + PL. 
\begin{tabular}{l|ll|ll} 
FP & 0.903316 & 0.9833165 & 0.8844694 & 0.9761021
\end{tabular}

of the grid injected current $\left(i_{g}\right)$ has been achieved. Furthermore, the PF at the grid side is increased from 0.88 to 0.98 .

In order to test the compliance with the IEEE1547 standard, the normalized amplitude respect to the fundamental harmonic, of the harmonics from the fundamental to the $17^{\text {th }}$ have been plotted. Fig. 16 shows the results obtained by using the conventional control scheme, whilst Fig. 18 shows the results obtained by using the proposed control scheme. The frequency of the polluted grid voltage has been chosen to be $55 \mathrm{~Hz}$.

By examining Fig. 16, it can be noticed that the harmonics of the inverter current as well as of the grid current, are over the maximum specified by the IEEE1546 norm. Furthermore, a $3^{\text {rd }}$ harmonic appears which is due to the ripple in the estimated phase due to the voltage unbalance. However, both the inverter and the grid current obtained when the ALSRF-PLL+PL is used meet the aforementioned standard, as it is clearly shown in Fig. 18. Furthermore, the $3^{\text {rd }}$ harmonic has been also rejected due to the adaptive filtering feature of the ALSRF-PLL.

The stability of the proposed control scheme has been tested by introducing a step in the grid frequency (i.e. by abruptly varying the frequency from $50 \mathrm{~Hz}$ to $55 \mathrm{~Hz}$ ). In Fig. 19 it is depicted the grid phase to phase voltage and the inverter current, $i_{i}$, when this frequency step takes place. By carefully examining this figure, it is clearly noticeable the settling time in the current, which recovers to the steady-state in almost one grid voltage cycle (i.e. the time needed by the ALSRF-PLL to estimate the new grid frequency).

Finally, the computing time of the conventional and of the proposed control schemes are shown in Table $\mathrm{X}$, when programmed in a fixed point DSP TI TMS320F2812.

\section{CONCLUSIONS}

A new control scheme has been presented, which is intended to be used in the StRF. The proposed ALSRF$\mathrm{PLL}+\mathrm{PL}$ is based on the adaptive GAL Schur-lattice IIR filter. This control scheme is able to track a time-varying frequency reference signal as well as to reject a time-varying frequency harmonics that may be present at the PCC voltage.

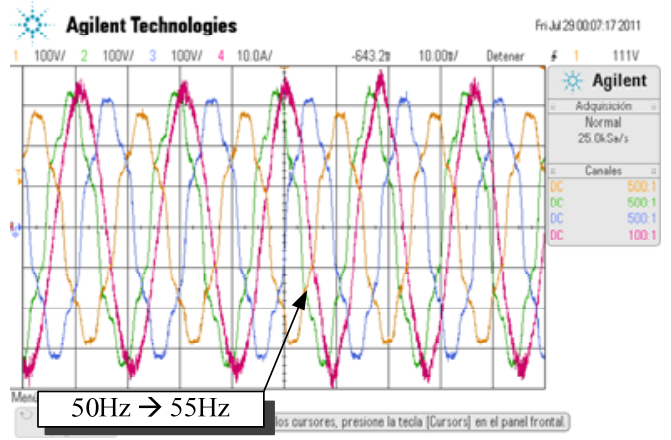

Fig. 19. Transient time response of the inverter generated current, $i_{i}$, controlled by means of the ALSRF-PLL + PL, when the frequency of the polluted voltage grid abruptly varies from $50 \mathrm{~Hz}$ to $55 \mathrm{~Hz}$.
The stability of the proposed control algorithm has been analytically proved, and the design guidelines have been presented. The experimental results obtained by means of a $10 \mathrm{KW}$ grid-connected PV inverter, digitally controlled by means of a floating point DSP, have shown that the ALSRF-PLL+PL allows to meet the most strict interconnection standards, even if the frequency of the grid voltage abruptly varies. The steady-state operation of the proposed control method allows obtaining a reduction from $7.1 \%$ to $0.8 \%$ in the THDi of the controlled current $\left(i_{i}\right)$, and from $8.5 \%$ to $4 \%$ in the THDi of the grid injected current $\left(i_{g}\right)$, when compared to the conventional SRF-PLL+PR control scheme. The PF at the grid side is increased from 0.88 to 0.98 .

TABLE X

COMPUTATIONAL TIME COMPARATIVE

\begin{tabular}{cc}
\hline \hline Control Strategy & Computational Time \\
\hline$S R F-P L L+P R$ & $10 \mu \mathrm{s}$ \\
$A L S R F+P L$ & $30 \mu \mathrm{s}$
\end{tabular}

\section{REFERENCES}

[1] J. M. Guerrero, F. Blaabjerg, T. Zhelev, K. Hemmes, E. Monmasson, S. Jemei, M. P. Comech, R. Granadino, and J. I. Frau, "Distributed Generation Toward a New Energy Paradigm," Industrial Electronics Magazine, IEEE, vol. 4, no. 1, Mar.2010, pp. 52-64.

[2] A. Tuladhar, H. Jin, T. Unger, and K. Mauch, "Parallel operation of single phase inverter modules with no control interconnections,", 1 ed Twelfth Annual Applied Power Electronics Conference and Exposition, 1997. APEC '97, 1997, pp. 94-100

[3] J. M. Guerrero, J. C. Vasquez, J. Matas, L. G. de Vicuna, and M. Castilla, "Hierarchical Control of Droop-Controlled AC and DC Microgrids-A General Approach Toward Standardization," IEEE Transactions on Industrial Electronics, vol. 58, no. 1, Jan.2011, pp. 158-172.

[4] K. De Brabandere, B. Bolsens, J. Van den Keybus, A. Woyte, J. Driesen, and R. Belmans, "A Voltage and Frequency Droop Control Method for Parallel Inverters," IEEE Transactions on Power Electronics, vol. 22, no. 4, 2007, pp. 1107-1115

[5] H. Jiabing and H. Yikang, "Modeling and Control of Grid-Connected Voltage-Sourced Converters Under Generalized Unbalanced Operation Conditions," IEEE Transaction on Energy Conversion, vol. 23, no. 3, 2008, pp. 903-913.

[6] A. Timbus, M. Liserre, R. Teodorescu, P. Rodriguez, and F. Blaabjerg, "Evaluation of Current Controllers for Distributed Power Generation Systems," IEEE Transactions on Power Electronics, vol. 24, no. 3, 2009, pp. 654-664

[7] D. N. Zmood, D. G. Holmes, and G. H. Bode, "Frequency-domain analysis of three-phase linear current regulators," IEEE transactions on Industry Applications, vol. 37, no. 2, 2001, pp. 601-610.

[8] V. Blasko and V. Kaura, "A new mathematical model and control of a three-phase AC-DC voltage source converter," IEEE Transactions on Power Electronics, vol. 12, no. 1, 1997, pp. 116-123.

[9] P. Mattavelli, "Synchronous-frame harmonic control for high-performance AC power supplies," Industry Applications, IEEE Transactions on, vol. 37, no. 3, 2001, pp. 864-872.

[10] V. M. Moreno, M. Liserre, A. Pigazo, and A. Dell'Aquila, "A Comparative Analysis of Real-Time Algorithms for Power Signal Decomposition in Multiple Synchronous Reference Frames," IEEE Transactions on Power Electronics, vol. 22, no. 4, 2007, pp. 1280-1289.

[11] H. Guan-Chyun and J. C. Hung, "Phase-locked loop techniques. A survey," IEEE Transactions on Industrial Electronics, vol. 43, no. 6, 1996, pp 609-615.

[12] C. Se-Kyo, "A phase tracking system for three phase utility interface inverters," IEEE transactions on Power Electronics, vol. 15, no. 3, 2000, pp 431-438.

[13] V. Kaura and V. Blasko, "Operation of a phase locked loop system under distorted utility conditions," IEEE transactions on Industry Applications, vol. 33 , no. 1,1997 , pp. 58-63.

[14] F. D. Freijedo, J. Doval-Gandoy, O. Lopez, and E. Acha, "Tuning of 
Phase-Locked Loops for Power Converters Under Distorted Utility Conditions," IEEE Transactions on Industry Applications, vol. 45, no. 6 , Nov.2009, pp. 2039-2047.

[15] S. Hong-Seok, P. Hyun-Gyu, and N. Kwanghee, "An instantaneous phase angle detection algorithm under unbalanced line voltage condition," 30th Annual IEEE Power Electronics Specialists Conference, 1999 (PESC 99), 1 ed 1999, pp. 533-537.

[16] A. V. Timbus, M. Ciobotaru, R. Teodorescu, and F. Blaabjerg, "Adaptive resonant controller for grid-connected converters in distributed power generation systems," 21 Applied Power Electronics Conference and Exposition. (APEC'06) 2006, p. 6.

[17] S. Lisheng and M. L. Crow, "A novel PLL system based on adaptive resonant filter," 40th North American Power Symposium, 2008. (NAPS '08) 2008, pp. 1-8.

[18] F. D. Freijedo, A. G. Yepes, O. pez, A. Vidal, and J. Doval-Gandoy, "Three-Phase PLLs With Fast Postfault Retracking and Steady-State Rejection of Voltage Unbalance and Harmonics by Means of Lead Compensation," IEEE Transactions on Power Electronics, vol. 26, no. 1, Jan.2011, pp. 85-97.

[19] P. Rodriguez, J. Pou, J. Bergas, J. I. Candela, R. P. Burgos, and D. Boroyevich, "Decoupled Double Synchronous Reference Frame PLL for Power Converters Control," IEEE Transactions on Power Electronics, vol. 22, no. 2, 2007, pp. 584-592.

[20] P. Rodriguez, A. Luna, I. Candela, R. Mujal, R. Teodorescu, and F. Blaabjerg, "Multi-Resonant Frequency-Locked Loop for Grid Synchronization of Power Converters Under Distorted Grid Conditions," IEEE Transactions on Industrial Electronics, vol. 58, no. 1, 2011, pp. 127138 .

[21] P. A. Regalia, "Stable and efficient lattice algorithms for adaptive IIR filtering," IEEE Transactions on Signal Processing, vol. 40, no. 2, 1992, pp. 375-388.

[22] M. Liserre, F. Blaabjerg, and S. Hansen, "Design and control of an LCLfilter-based three-phase active rectifier," IEEE Transactions on Industry Applications, vol. 41, no. 5, 2005, pp. 1281-1291.

[23] N. Mohan, T. M. Undeland, and W. P. Robbins, Power Electronics. Converters, applications, and design., 3rd. ed. John Wiley \& Sons, Inc., 2003.

[24] B. A. Francis and W. M. Wonham, "The internal model principle of control theory," Automatica, vol. 12, no. 5, Sept.1976, pp. 457-465.

[25] P. A. Regalia, Adaptive IIR filtering in signal processing and control. Marcel Dekker, INC., 1995.

[26] P. P. Vaidyanathan and S. K. Mitra, "A unified structural interpretation of some well-known stability-test procedures for linear systems," Proceedings of the IEEE, vol. 75, no. 4, Apr.1987, pp. 478-497.

[27] F.González-Espín, E.Figueres, G.Garcerá, “An Adaptive SynchronousReference-Frame Phase-Locked Loop for Power Quality Improvement in a Polluted Utility Grid", IEEE Transactions on Industrial Electronics", vol.59, no. 6, Jun.12, pp. 2718-2731.

[28] S. Haykin, Adaptive filter theory. Prentice Hall, 2002.

[29] A. K. Kohli and D. K. Mehra, "Tracking of time-varying channels using two-step LMS-type adaptive algorithm," IEEE Transactions on Signal Processing, vol. 54, no. 7, July2006, pp. 2606-2615.

[30] Carugati, I.; Maestri, S.; Donato, P.G.; Carrica, D.; Benedetti, M.; , "Variable Sampling Period Filter PLL for Distorted Three-Phase Systems," IEEE Transactions on Power Electronics, vol.27, no.1, pp.321-330, Jan. 2012 